\title{
Growth Cones Are Actively Influenced by Substrate-Bound Adhesion Molecules
}

\author{
Susan M. Burden-Gulley, H. Ross Payne, and Vance Lemmon \\ Department of Neurosciences, Case Western Reserve University, Cleveland, Ohio 44106
}

\begin{abstract}
As axons advance to appropriate target tissues during development, their growth cones encounter a variety of cell adhesion molecules (CAMs) and extracellular matrix molecules (ECM molecules). Purified CAMs and ECM molecules influence neurite outgrowth in vitro and are thought to have a similar function in vivo. For example, when retinal ganglion cell (RGC) neurons are grown on different CAM and ECM molecule substrates in vitro, their growth cones display distinctive morphologies (Payne et al., 1992). Similarly, RGC growth cones in vivo have distinctive shapes at different points in the pathway from the eye to the tectum, suggesting the presence of localized cues that determine growth cone behaviors such as pathway selection at choice points.
\end{abstract}

In this report, time-lapse video microscopy was utilized to examine dynamic transformations of RGC growth cones as they progressed from L1/8D9, N-cadherin, or Iaminin onto a different substrate. Contact made by the leading edge of a growth cone with a new substrate resulted in a rapid and dramatic alteration in growth cone morphology. In some cases, the changes encompassed the entire growth cone including those regions not in direct contact with the new substrate. In addition, the growth cones displayed a variety of behavioral responses that were dependent upon the order of substrate contact. These studies demonstrate that growth cones are actively affected by the substrate, and suggest that abrupt changes in the molecular composition of the growth cone environment are influential during axonal pathfinding.

[Key words: growth cone, $L 1, N$-cadherin, laminin, retinal ganglion cell, pathfinding]

The formation of proper neural connections in the brain and with peripheral tissues occurs during early stages of development. In many cases, axons must traverse long distances through a complex environment composed of a variety of molecules and cell types before reaching their target tissues. The development of proper connections is critical and may involve several different mechanisms. In some cases it appears that axons grow passively in preformed pathways surrounded by tissues that act as mechanical barriers (Krayanek and Goldberg, 1981). In other cases,

Received Sept. 30, 1994; revised Dec. 12, 1994; accepted Dec. 16, 1994. We thank Dr. Lynn Landmesser for helpful comments on the manuscript. We also acknowledge the excellent technical support of Gwendolynne Elmslie. A portion of this work was presented in abstract form at the 1992 annual meeting of the Society for Neuroscience. This research was supported by National Eye Institute Grant 5285

Correspondence should be addressed to V. Lemmon at the above address.

Copyright (C) 1995 Society for Neuroscience $\quad 0270-6474 / 95 / 154370-12 \$ 05.00 / 0$ axonal growth is selective in that axons actively navigate to their targets by detecting positive and negative chemical cues in their environment that influence pathway choice (e.g., neurotrophins, cell adhesion molecules, extracellular matrix molecules, and proteoglycans) (Landmesser, 1984; Silver and Rutishauser, 1984; Lumsden and Davies, 1986; Dodd and Jesse1l, 1988; Heffner et al., 1990; Brittis et al., 1992; Tang et al., 1992; Oakley and Tosney, 1993).

Each axon possesses a highly motile, membranous structure at its terminus called a growth cone that acts as a sensory organ during this outgrowth period. In vitro, growth cones continually extend and retract broad membranous sheets of lamellipodia and finer spike-like filopodial processes that can be up to several tens of micrometers long. Growth cones are thought to use these membranous extensions to actively explore their environment and interact with cells in their path.

Axonal pathfinding has been studied extensively in several model systems, including the grasshopper limb (O'Connor et al., 1990), Drosophila CNS (Grenningloh et al., 1991; Seeger et al., 1993), rodent corpus callosum (Halloran and Kalil, 1994), chick hindlimb (Tosney, 1991; Tang et al., 1992), and the retinotectal pathway (Bovolenta and Mason, 1987; Cux el al., 1990; Godement et al., 1990; Kaethner and Stuermer, 1992; Chien et al., 1993; Stretavan et al., 1994). The retinotectal pathway has proven to be a good system for these studies because it is well characterized and readily accessible (Holt and Harris, 1993). During development of the chicken retinotectal pathway, retinal ganglion cells (RGCs) send out axons by embryonic day 2.5 (stage 16) toward the optic fissure (Halfter et al., 1983). The axons travel through the optic nerve to the chiasm where they cross to innervate the tectum on the contralateral side.

During this period of outgrowth, the axons come into contact with several different cell adhesion molecules (CAMs) and extracellular matrix (ECM) molecules including L1/8D9 (Lemmon and McLoon, 1986), N-cadherin (Matsunaga et al., 1988), R-cadherin (Inuzuka et al., 1991), neural cell adhesion molecule (NCAM) (Thiery et al., 1982; Schlosshauer et al., 1984), and the ECM molecule laminin (Cohen et al., 1987). When purified from embryonic tissues and used as a substrate in culture, these CAMs and ECM molecules support the outgrowth of neurites from different types of neurons, as well as the adhesion and migration of several non-neuronal cell types (Reichardt and Tomaselli, 1991; Doherty and Walsh, 1992; Lemmon et al., 1992). Therefore, it is thought that these molecules, individually or in concert, may play similar roles in the embryo.

Several theories have been offered for how CAMs and ECM molecules might direct the outgrowth of axons toward their appropriate target tissues. Initially, it was suggested that axons 
choose the most adhesive pathway availahle (I etourneau, 1975a,b; Hammarback et al., 1988), but subsequent in vitro experiments (Gundersen, 1987, 1988; Lemmon et al., 1992) have shown that the relative adhesiveness of a substrate is a poor predictor of the choices neurites make between two substrates.

Another theory is that the binding of CAMs and ECM molecules may be transduced into an intracellular signaling cascade that is important for growth cone pathfinding. It has been shown that the addition of purified CAMs or antibodies directed against the CAMs to PC12 cells, primary neurons, or Schwann cells results in changes in intracellular $\mathrm{pH}, \mathrm{Ca}^{2+}, \mathrm{IP}_{2}$, and $\mathrm{IP}_{3}$ levels (Schuch et al., 1989; Halbach et al., 1992). Doherty and colleagues have provided evidence suggesting that an erbstatin-sensitive tyrosine kinase (Williams et al., 1994b), arachidonic acid (Williams et al., 1994a), and $G$ protcin-dependent activation of $\mathrm{Ca}^{2+}$ channels may be involved in neurite outgrowth on $\mathrm{N}$-cadherin-, L1-, or NCAM-expressing 3T3 cells, but not on those expressing laminin (Doherty et al., 1991; Safell et al., 1992; Williams et al., 1992). In addition, Ignelzi and colleagues have recently shown that the tyrosine kinase pp60-sic may play a partial role in L1-mediated neurite outgrowth (Ignelzi et al., 1994). In contrast, protein kinase $C$ is apparently involved in neurite outgrowth on laminin, fibronectin, and collagen but not on Ll or $\mathrm{N}$-cadherin, suggesting that integrin-mediated signaling utilizes distinct signaling pathways (Bixby and Jhabvala, 1990). Together, these results suggest that cellular interaction with CAMs and ECM molecules produces intracellular signals that are involved in the initiation of neurite outgrowth and possibly other, as yet undefined, cellular responses.

RGC growth cones and neurites in vitro display distinct morphologies and growth characteristics dependent upon the substrate (Lemmon et al., 1992; Payne et al., 1992). On L1/8D9, the growth cones are large, fan shaped, and predominantly lamellipodial, although they exhibit quite a few short filopodia. Neurites on L1/8D9 form a dense but defasciculated monolayer. In contrast, growth cones on laminin display a smaller lamellipodial region and have fewer filopodia, but the filopodia are more than one-third longer than those on L1/8D9. Neurites on laminin are highly fasciculated and tend to grow as tight bundles of several neurites together. On N-cadherin, growth cones are lamellipodial in nature with many short filopodia. These growth cones are smaller than those on L1/8D9, but are significantly larger and flatter than those on laminin. RGC neurites on $\mathrm{N}$-cadherin are generally defasciculated, although small bundles of two or three neurites are observed occasionally. These differences in morphology are likely a result of changes in cytoskeletal architecture that result from the binding of $\mathrm{C} \triangle \mathrm{M}$ or $\mathrm{ECM}$ receptors with their appropriate ligand. In addition, growth cone contact with CAMs or ECM molecules may result in the production of intracellular signals that precede specific growth cone behavioral changes. It is important to understand how abrupt changes in the types of molecules encountered can affect growth cone behavior, since $\mathrm{RGC}$ growth cones grow through a rapidly changing cellular environment en route to their target.

In the studies reported here, time-lapse video microscopy was used to examine chick RGC growth cones as they interacted with a sharp border between L1 and laminin, or N-cadherin and laminin. The results indicate that growth cones are actively affected by the substrate. For example, as a growth cone crossed over onto a new substrate, it underwent dramatic morphological changes to a shape characteristic for the new substrate even though its neurite and the proximal portion of the growth cone remained on the initial substrate. A variety of behavioral responses were observed at border regions including cross without delay, collapse, retraction, and turning to remain on the initial substrate. These responses were associated with particular substrate border combinations, suggesting that contact with certain substrates may elicit signal cascades in the growth cone that are necessary for appropriate pathfinding.

\section{Materials and Methods}

Preparation of substrates. Black, round nitrocelluluse filters $(0.45 \mu \mathrm{mI}$ pore size, $25 \mathrm{~mm}$ diameter) from Sartorius (Hayward, CA) were used to secure retinal explants to the culture dish. Nitrocellulose $(0.45 \mu \mathrm{m}$ pore size, grade BA85) for coating of coverslips was obtained from Schleicher and Schuell (Keene, NH). Laminin was obtained from GIBCO-Bethesda Research Labs (Grand Island, NY), and polylysine from Sigma (St. Louis, MO). Rat L1 and chick L1/8D9 were purified from brains using an affinity column conjugated with $74-5 \mathrm{H} 7$ (Lemmon et al., 1989) or 8D9 (Lemmon and McLoon, 1986) antibodies, respectively. N-cadherin was purified using antibody NCD-2 (Hatta and Takeichi, 1986) as described by Bixby and Zhang (1990).

The culture chamber consisted of a $60 \mathrm{~mm}$ tissue culture dish with a hole drilled through the bottom. An acid-washed glass coverslip (Fisher, Pittsburgh, PA) was glued to the bottom of the dish with SILASTIC medical adlhesive (Dow Coning, Midland, MI) and allowed to dry, and the dish was UV irradiated. The coverslip was coated with $0.1 \mathrm{mg} / \mathrm{ml}$ polylysine in $\mathrm{dHOH}$ overnight at $37^{\circ} \mathrm{C}$, then rinsed with distilled water and air dried. A thin layer of nitrocellulose solution (Lagenaur and Lemmon, 1987) was spread across the coverslip and allowed to dry. A $2 \times 20 \mathrm{~mm}$ piece of sterile filter paper was laid on the coverslip and saturated with the first substrate protein (L1, laminin, or N-cadherin; $100 \mu \mathrm{g} / \mathrm{ml}$ ) for a $15 \mathrm{~min}$ incubation. A small amount of rhodaminelabeled bovine serum albumin (BSA) was included in this solution to mark the position of the substrate stripe. The stripe was then blocked with $2 \%$ BSA in $\mathrm{Ca}^{2+} / \mathrm{Mg}^{2+}$-free Hank's buffer (CMF) for $10 \mathrm{~min}$, the filter paper was removed, and the stripe was rinsed with distilled water. The second substrate protein was spread adjacent to and in contact with the first substrate stripe, and incubated for $15 \mathrm{~min}$. This procedure resulted in a continuous coating of substrate proteins, with an abrupt transition between the two substrates at a point denoted as the border region. The entire coverslip was then blocked with $2 \%$ BSA in CMF for $10 \mathrm{~min}$ and stored at $37^{\circ} \mathrm{C}$ covered with RPMI medium until used for plating $(\sim 30 \mathrm{~min})$

Preparation of retinal explant strips. Retinal explants from White Leghorn chick embryos (embryonic day 7, corresponding to Hamburger and Hamilton stages 29-30) were plated as previously described (Halfter et al., 1983; Drazha and I emmon, 1990) using media consisting of RPMI 1640/10\% fetal bovine serum/2\% chick serum (CS)/penicillinstreptomycin-fungizone (PSF). Retinas were cut at $350 \mu \mathrm{m}$ intervals, perpendicular to the optic fissure. Explants were inverted and oriented parallel to the substrate border as they were placed on the coverslips in culture dishes. This resulted in outgrowth of retinal ganglion cell (RGC) axons at a roughly perpendicular orientation to the border. The cultures were incubated overnight at $37^{\circ} \mathrm{C}$ in $5 \% \mathrm{CO}_{2}, 95 \%$ air before use for the time-lapse studies.

Iime-lapse video microscopy. 'The cultures were removed from the incubator after approximately $24 \mathrm{hr}$ and the medium exchanged with prewarmed HEPES-DMEM/10\% FBS/2\% CS/PSF. The cultures were coverslipped and transferred to the stage of the microscope (Zeiss Axiovert $405 \mathrm{M}$ ) that was fitted with an incubation chamber and maintained at $37^{\circ} \mathrm{C}$. (Nikon NP-2 incubator). After a $1 \mathrm{hr}$ equilibration on the microscope stage, time-lapse recording was begun. For these experiments, a $40 \times$ or $100 \times$ oil immersion phase objective was used. Since the RGC growth cones were very sensitive to light, images were collected at low light levels with a silicon intensified target (SIT) camera (Dage MTI65 or a Hamamatsu SIT camera with an Argus 10 processor). A Uniblitz shutter was used to minimize light exposure during intervals between image collection. Images were collected at $30 \mathrm{sec}$ intervals (IMAGE-1, Universal Imaging), with 64 frames averaged per image, and stored on a Panasonic optical disk for later analysis. Cells remained healthy for longer than $10 \mathrm{hr}$ on the microscope stage, with individual growth cones recorded for as long as $4 \mathrm{hr}$ with no adverse effects.

Since the RGC growth cones tended to grow out in a wave from the explants, individual growth cones at the front of the wave were gen- 
Table 1. Growth cone interactions at substrate borders

\begin{tabular}{lllllll} 
& Cross & Turn & Collapse & $\begin{array}{l}\text { Retract } \\
(>10 \mu \mathrm{m})\end{array}$ & Delay & $\begin{array}{c}\text { Average delay } \\
\text { (min) }\end{array}$ \\
\hline $\begin{array}{l}\text { Laminin } \rightarrow \text { L1/8D9 } \\
\quad(n=17)\end{array}$ & 100 & 0 & 59 & 18 & 35 & 7 (cross) \\
$\begin{array}{l}\text { L } 1 / 8 \mathrm{D} 9 \rightarrow \text { Laminin } \\
\quad(n=23)\end{array}$ & 75 & 35 & 17 & 0 & 44 & $\begin{array}{l}44 \text { (cross) } \\
40 \text { (turn) } \\
\text { Laminin } \rightarrow \text { N-cadherin } \\
\quad(n=22)\end{array}$ \\
$\begin{array}{l}\text { N-cadherin } \rightarrow \text { Laminin } \\
(n=30)\end{array}$ & 100 & 4 & 41 & 0 & 14 & $\begin{array}{c}17 \text { (cross) } \\
0 \text { (turn) } \\
40 \text { (cross) } \\
24 \text { (turn) }\end{array}$
\end{tabular}

Results are listed as percentage of total.

erally selected for time-lapse. These growth cones were usually 50-100 $\mu \mathrm{m}$ away from the border region at the start of recording to allow for assessment of growth rate, and that their path toward the border would be clear of any other neurons or debris. An image of the fluorescent border boundary was collected at the start and tinish of each recording sequence to ensure that the dish had not moved during recording, and to define specifically where the growth cone contacted the border region. No transition could be seen between the two substrates using phase contrast optics, suggesting that the border did not present a physical barrier

Analysis of time-lapse sequences. Growth cones that contacted the border region without interference from other growth cones were selected for further analysis. Several types of interactions were observed, including an immediate cross onto the other substrate, collapse, or retraction upon contact with the border, turning and growing along the edge of the first substrate, or a delay of variable time followed by a cross or turn. Growth cones displayed any combination of these interactions, and were therefore examined individually. These interactions were analyzed by preparing traces of each growth cone on transparencies at $1-15$ min intervals as the growth cone grew on the first substrate, interacted with the border, and grew beyond. The traces were used to categorize growth cone response at the border, measure changes in growth rate, and illustrate the morphological changes in the growth cones as they grew onto a new substrate. Growth rate and growth cone area measurements were made from the traces with a BIOQUANT IMAGE ANALYSIS SYSTEM IV.

The time lapse series shown in Figures 1-6 were produced as follows. Using the IMAGE-1 software, a dashed line was painted along the fluorescent border image for each field. This line was overlaid onto the contesponding phase contrast images, and the selected regions from each image were pasted together in a time-lapse series image. Each resultant image was enhanced further (PHOTOSHOP 2.0.1 software) by changing the background to a lighter level. Time-lapse series images were printed using a Kodak XLS 800 digital printer.

\section{Results}

Time-lapse video microscopy was used to examine growth cones as they interacted with a sharp border region between $\mathrm{L} 1 / 8 \mathrm{D} 9$ or N-cadherin and laminin. The use of retinal explants for these experiments provided a homogeneous group of ganglion cell axons that grew out in a wave toward the border region. Due to this outgrowth pattern, those growth cones at the front of the wave were used for analysis. It should be noted that growth cones behind the front of the wave also behaved similarly even though they were in contact with other neurites and growth cones at the time of border contact. At the border region, several behaviors were observed such as crossing onto the second substrate, turning to remain on the first substrate, or transient retraction. In addition, a collapse response was observed consisting of the involution of lamellipodial and filopodial processes resulting in a decrease in growth cone size. Unlike the collapse that has previously been described following contact with inhibitory cues (Kapfhammer and Raper, 1987a; Davies et al., 1990;
Luo et al., 1993), the collapse response observed here was associated with only a temporary loss of protrusive activity. The observed behaviors occurred individually (e.g., immediate cross) or in combinations (e.g., collapse followed by a turn) and were characteristic of the order in which substrates were contacted. Delays of variable length were also observed after contact with the border region.

\section{Growth cone interactions at the interface of laminin and $N$-cadherin}

RGC neurites growing on laminin tended to remain in fascicles of various sizes. For the time-lapse studies described below, small-diameter fascicles were followed as they grew toward the border region. When growth cones growing on laminin contacted the N-cadherin border, $100 \%$ of the growth cones $(n=22)$ crossed onto $\mathrm{N}$-cadherin (Table 1). During the cross, the growth cones underwent a characteristic shape change from a small, predominantly filopodial morphology on laminin to a much larger and flattened appearance as they migrated onto the $\mathrm{N}$-cadherin (Fig. 1). This change occurred progressively: the portion of the growth cone on $\mathrm{N}$-cadherin displayed the flattened morphology even though the rear portion of the growth cone and the neurite were in contact with laminin and displayed morphology appropriate to laminin. The growth cones were also observed to separate from one another as they progressed onto the $\mathrm{N}$-cadherin, resulting in defasciculation of the neurites. One growth cone turned at the border and grew for $15 \mathrm{~min}$ on the laminin before finally crossing (included in Table 1 under both cross and turn categories). Only $14 \%(n=3)$ of the growth cones delayed after contact with the border for an average time of $17 \mathrm{~min}$ before crossing onto the $\mathrm{N}$-cadherin (see Table 1). Interestingly, $41 \%$ $(n=9)$ were observed to collapse transiently upon contact with the $\mathrm{N}$-cadherin, but none retracted prior to crossing. The collapse occurred coincident with or within 5 min of border contact, and lasted less than $5 \mathrm{~min}$ on average before the growth cone recovered its initial size. Collapse resulted in a slight decrease in growth rate in three cases that was recovered within the next 5 min. In the remaining six cases, collapse had no effect on growth rate.

In the opposite situation, 30 growth cones were analyzed as they initiated growth on $\mathrm{N}$-cadherin and then interacted with a laminin border. Of these, $60 \%(n=18)$ crossed onto the laminin. Three of these growth cones delayed an average of $40 \mathrm{~min}$ at the laminin border prior to crossing (Table 1). It should be pointed out that the growth cones at the wave front and those arriving later were observed to congregate at the border region before crossing onto the laminin (not shown). In many cases, individual 

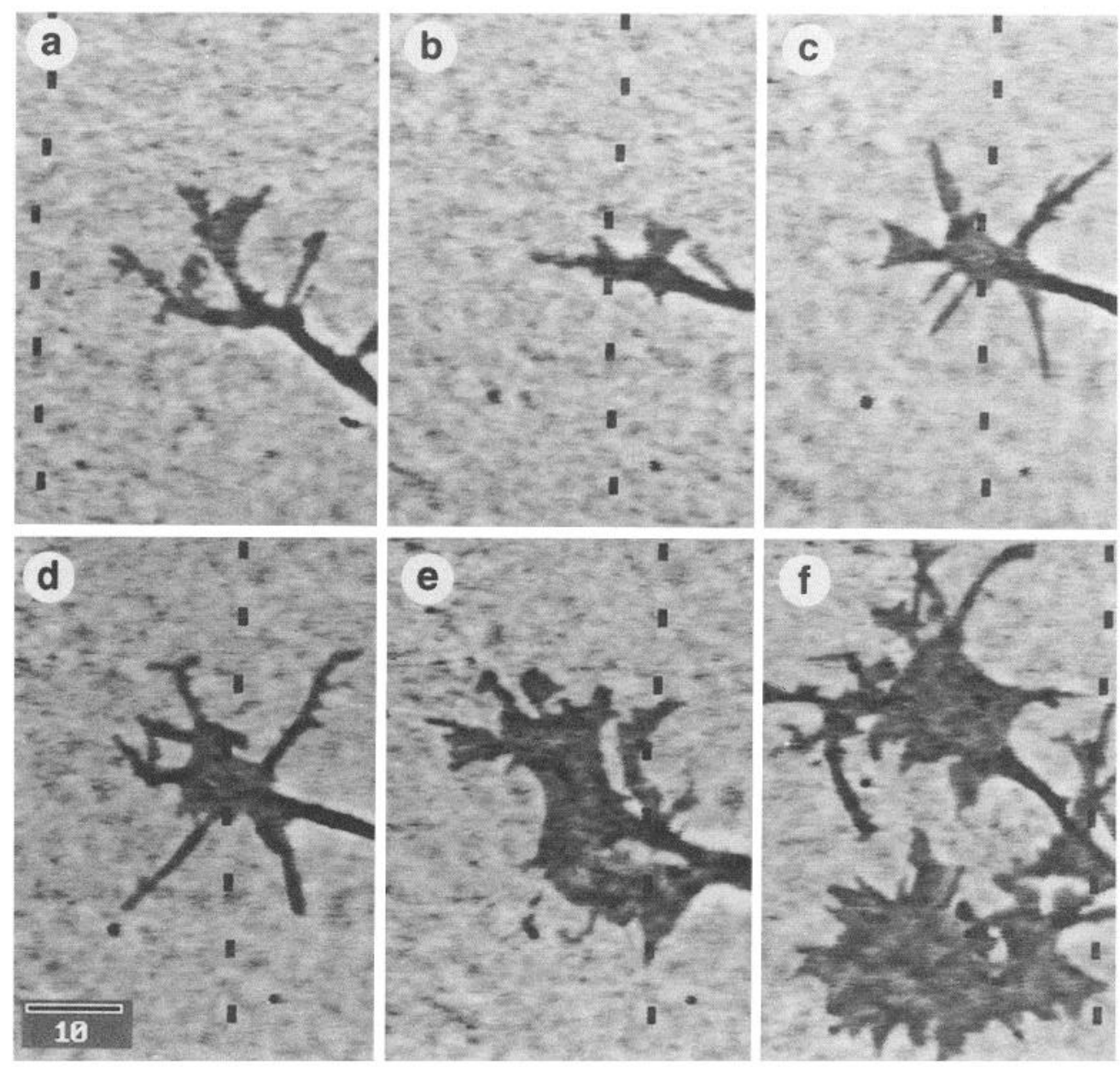

Figure 1. Time-lapse series of a growth cone initiating growth on laminin and contacting $\mathrm{N}$-cadherin at a border region. Images of the growth cone are shown at 0:00 (a), 4:00 (b), 5:00 (c), 5:30 (d), 9:30 (e), and 14:30 $(f)$ min progressed time from first frame (a) (time denoted as min:sec). The border between substrates is indicated by the dashed line. The selected field area was moved to the left in $b$, $e$, and $f$ to accommodate forward progress of the growth cone. Compare the slender, branched growth cone on laminin $(a)$ with the much larger, flattened growth cone on $\mathrm{N}$-cadherin $(e, f)$. Note the rapid change in morphology of the growth cone that occurs progressively $(b-d)$, and the defasciculation of neurites $(e, f)$ after contact with the $\mathrm{N}$-cadherin border. Scale bar, $10 \mu \mathrm{m}$. growth cones extended long, thickened filopodia-like processes onto the laminin several times before crossing (Fig. 2). Most growth cones crossed as bundles of two or more at a time, and growth cones behind the wave front tended to cross onto laminin by fasciculating along neurites of growth cones that had crossed previously. One growth cone crossed onto laminin and grew for a brief period, then turned back to grow on the $\mathrm{N}$-cadherin for the remainder of the recording session. This growth cone was included in both the cross and turn categories in Table 1. Overall, $43 \%(n=13)$ of the growth cones turned at the laminin border. None of these growth cones were observed to later cross onto laminin, but rather, grew on $\mathrm{N}$-cadherin at the border for the remainder of the recording session (Fig. 3). Seven of the growth cones illustrated an average delay prior to turning of 24 min after contact with the laminin border. In the group of growth cones at the wave front, $30 \%(n=9)$ collapsed transiently, and $10 \%(n=3)$ retracted briefly by $12 \mu \mathrm{m}$ on average upon contact with the border. Collapse occurred coincident with or within 5 min of border contact. In seven cases, recovery occurred within $5 \mathrm{~min}$ of collapse, even though retraction was associated with two of these cases. In the remaining two cases of collapse, recovery occurred within $10-50 \mathrm{~min}$. Collapse resulted in a transient $(<5 \mathrm{~min})$ decrease in growth rate in five cases, but had no effect on growth rate in the remaining three cases. Five growth cones turned to grow along the border after the collapse response, whereas the remaining four crossed onto the laminin. Comparison of the frequency of behaviors observed in this substrate combination with those of growth cones initiating on lam- inin (see Table 1) suggests that the order of substrate contact significantly affects growth cone response.

The growth cone morphology changes observed at border regions occurred rapidly after initial contact (see Fig. 7). Growth cones initiating on $\mathrm{N}$-cadherin underwent a $40 \%$ decrease in area within the first minute after contact with the laminin border. This change occurred even though the majority of growth cones had contact only via the leading-edge lamellipodium. The area changed little during the next few minutes, but decreased by a total of $57 \%$ after the cross onto laminin was completed. In growth cones initiating on laminin, the area increased by $20 \%$ within the first minute of contact with the $\mathrm{N}$-cadherin border, but increased by an additional $70 \%$ within the following 4 min. After the cross onto $\mathrm{N}$-cadherin was completed, the area increased by $188 \%$ over the initial area observed on laminin (representative traces of growth cones undergoing morphological changes at $\mathrm{N}$-cadherin-laminin borders are shown in Fig. 8). These results indicate that the growth cones are very sensitive to changes in substrate, and actively respond to new substrate cues through modifications in morphology.

\section{Growth cone interactions at the interface of laminin and LI/ $8 D 9$}

Growth cones that initiated growth on laminin were analyzed as they contacted a border of L1/8D9 $(n=17)$. All of these growth cones crossed onto the L1/8D9, with only $35 \%(n=6)$ delaying an average of $7 \mathrm{~min}$ prior to crossing (Table 1). As growth cones crossed onto L1/8D9, they progressively changed from the 

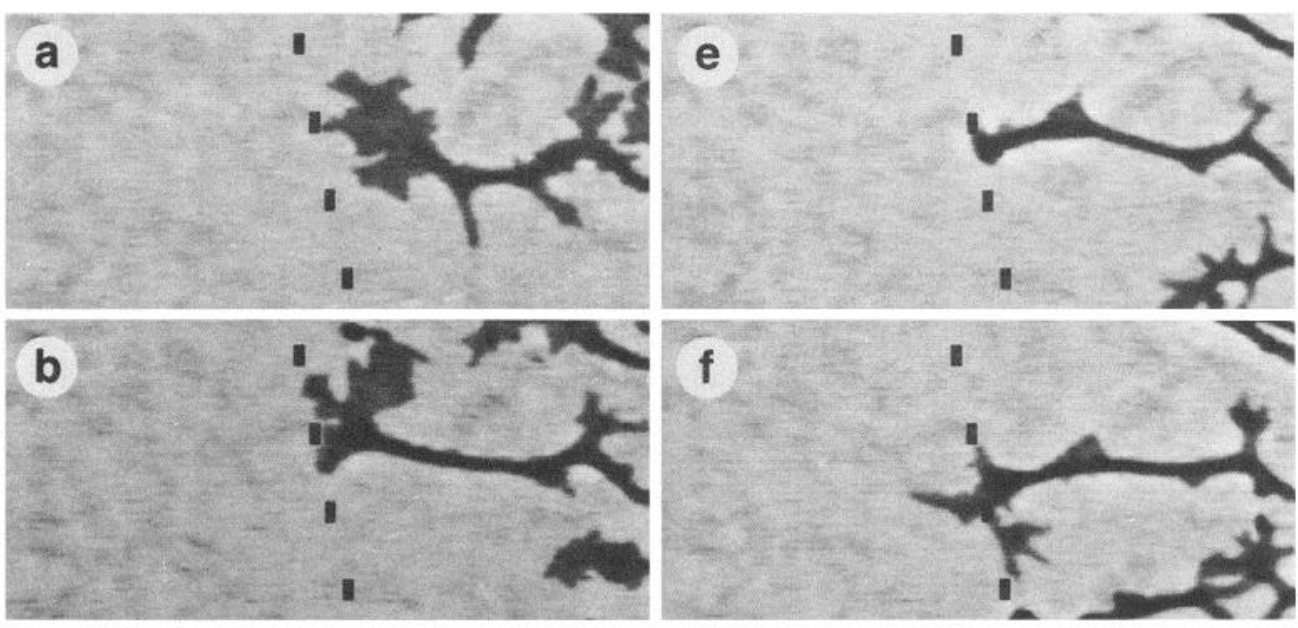

Figure 2. Time-lapse series of a growth cone initiating growth on $\mathrm{N}$-cadherin and contacting laminin at a border region. Images of the growth cone are shown at 0:00 $(a), 8: 00(b), 10: 00$ $(c), 14: 00(d), 15: 00(e), 42: 30(f), 50$ : $30(\mathrm{~g})$, and 59:00 $(\mathrm{h}) \mathrm{min}$ progressed time from first frame $(a)$ (time denoted as min:sec). The border is indicated by the dashed line. Note the rapid decrease in growth cone size after first contact with laminin $(c)$, and the long delay from initial contact until completed cross $(b-h, 51: 00 \mathrm{~min})$. Thick, filopodia-like processes were extended onto the laminin $(d)$ and retracted multiple times (not shown) prior to final cross $(h)$, as if the growth cone was sampling the new environment. Scale bar, $10 \mu \mathrm{m}$.
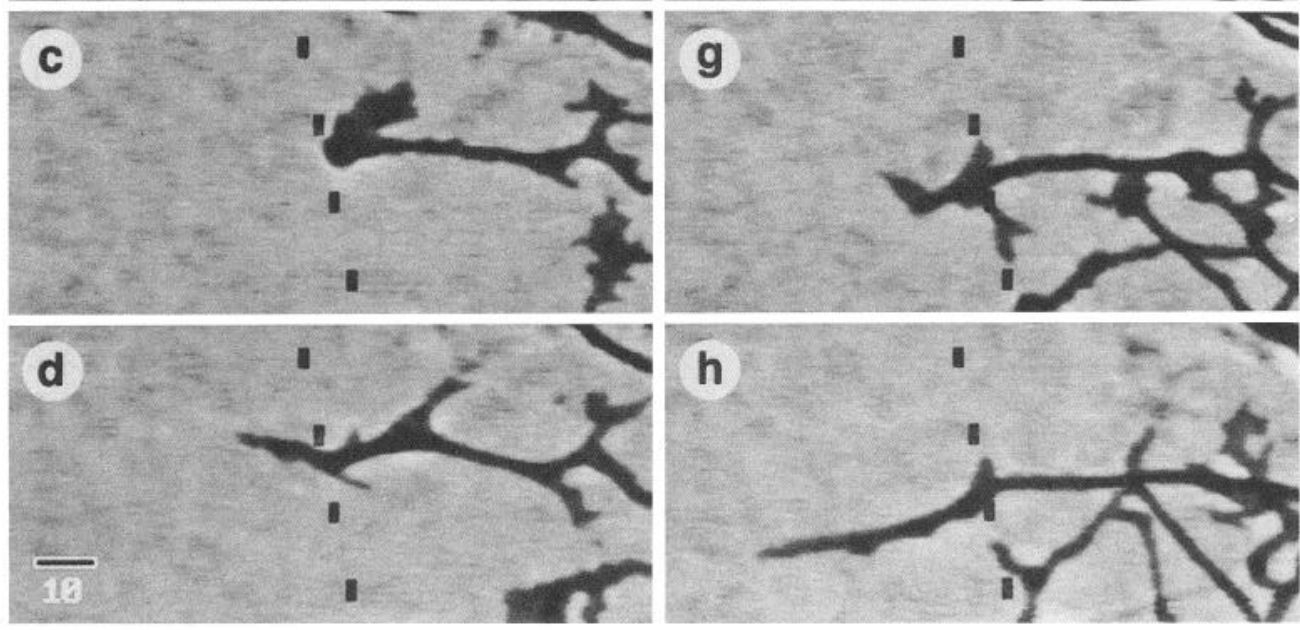

small, predominantly filopodial morphology characteristic of laminin to a much larger, fan-shaped growth cone (Figs. 4, 5). Growth cone advance onto the L1/8D9 resulted in a progressive defasciculation of neurites similar to that observed on N-cadherin. None of the growth cones were observed to turn at the border to continue growth on laminin. Interestingly, 59\% $(n=$ 10) of the growth cones collapsed upon contact with the border, while only $18 \%(n=3)$ retracted at least $10 \mu \mathrm{m}$ (average 10 $\mu \mathrm{m})$. Collapse occurred less than $5 \mathrm{~min}$ after contact, and all growth cones recovered within $5 \mathrm{~min}$ after collapse. In four cases, collapse was associated with a transient decrease in growth rate, but in the remaining six cases no effect on growth rate was observed. All growth cones that retracted displayed a collapse just prior to retraction. A few growth cones were observed to collapse after border contact, and upon second contact the growth cones changed morphology to one appropriate to L1/ 8D9 even though most of the growth cone was still on laminin (Fig. 4).

In the opposite situation, growth cones initiating growth on L1/8D9 $(n=23)$ crossed onto laminin less frequently (75\% of the time, $n=17)$ (Fig. 6), and 35\% $(n=6)$ of them delayed $44 \mathrm{~min}$ on average prior to crossing (Table 1). The growth cones were observed to congregate at the border region in a similar fashion as on $\mathrm{N}$-cadherin, and usually crossed onto laminin as bundles of two or more growth cones. Often, the growth cones produced filopodial or lamellipodial extensions that appeared to sample the laminin several times prior to crossing. Growth cones behind the wave front tended to cross onto laminin by fascicu- lating along the neurites that had crossed previously. $35 \%(n=$ 8 ) of the growth cones turned at the border to continue growth on L1/8D9. Four of these growth cones turned without delay, while the remaining four delayed an average of $40 \mathrm{~min}$ prior to turning. Two of the growth cones that turned at the border later crossed onto the laminin (included in Table 1 under both cross and turn categories), but the remaining six growth cones that turned maintained growth on the L1/8D 9 at the border for the remainder of the recording session. A small percentage of growth cones $(17 \%, n=4)$ collapsed upon first contact with laminin, but none of them were observed to retract greater than $10 \mu \mathrm{m}$. In all cases, collapse occurred coincident with or within $8 \mathrm{~min}$ of contact, and each growth cone recovered within $5 \mathrm{~min}$ of collapse. Two of the growth cones that turned to grow along the border displayed a collapse prior to turning. Collapse was associated with a slight decrease in growth rate that lasted for less than $5 \mathrm{~min}$ in three cases, and a more extensive decrease in growth rate that lasted for approximately $20 \mathrm{~min}$ in one case. Comparison of the frequency of behaviors in this substrate combination suggests that the order of substrate contact significantly affects growth cone response.

Growth cone area measurements made prior to, during, and after border contact revealed that growth cones responded rapidly to a change in substrate (Fig. 7). For example, growth cones initiating on L1/8D9 showed a nearly $40 \%$ decrease in area within the first minute of contact with the laminin border. Growth cones completing the cross onto laminin displayed a $62 \%$ total decrease in area from original levels observed on L1/8D9. In 

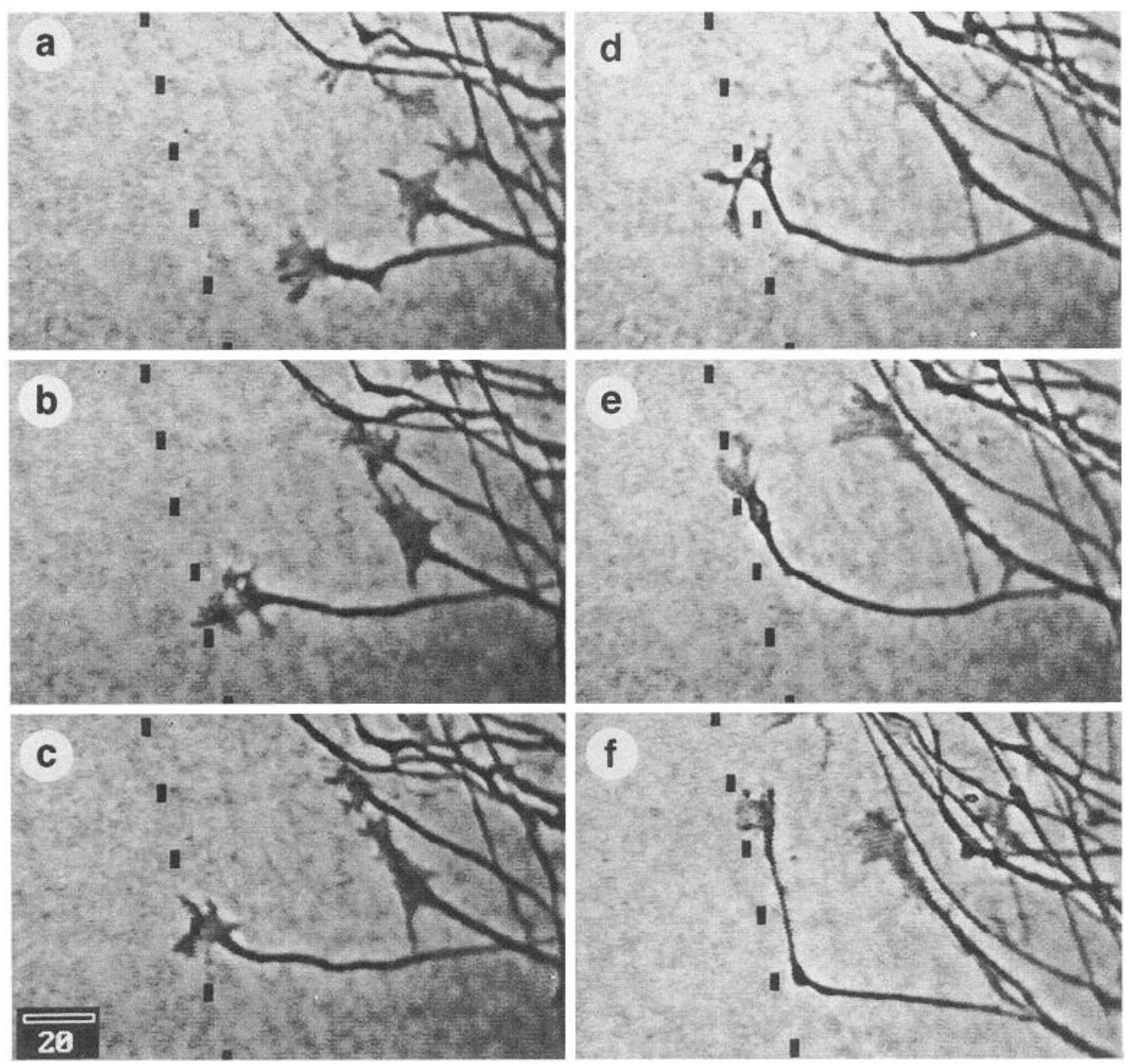

Figure 3. Time-lapse series of a growth cone initiating growth on $\mathrm{N}$-cadherin and contacting laminin at a border region. Images of the growth cone are shown at 0:00 (a), 14:30 (b), 19:30 $(c), 30: 00(d), 33: 00(e)$, and 46:00 $(f)$ min progressed time from first frame (a) (time denoted as min:sec). The border is indicated by the dashed line. The growth cone approaches the border at a nearly perpendicular angle, but after contact with laminin $(b, c)$, it turns to continue growing on $\mathrm{N}$-cadherin $(f)$. Note the thick processes extended onto the laminin $(d)$ for sampling of the substrate even though the main portion of the growth cone remains on $\mathrm{N}$-cadherin. The selected field area was moved up in $f$ to accommodate forward progress of the growth cone. Growth cones just out of the field above crossed onto the laminin substrate. Scale bar, $20 \mu \mathrm{m}$. the opposite situation, growth cones initiating on laminin showed a $48 \%$ increase in area within the first minute of contact with the L1/8D 9 border. After the cross onto L1/8D9 was completed, the area increased by $169 \%$ over the initial area observed on laminin. The rapid change in area cannot be attributed to differences in adhesivity alone since the region of contact with the new substrate was confined to the leading-edge lamellipodium in the majority of growth cones measured. Representative examples of the extent of changes in growth cone area are shown in Figure 8. Together, these results show that CAMs and ECM molecules used as a substrate can actively influence growth cone morphology and behavior.

\section{Discussion}

Time-lapse video microscopy is a powerful tool that provides important information about cell behavior. It has been used by many investigators to examine a variety of cell-cell and cellsubstrate interactions in vitro, as well as in vivo processes such as growth cone pathfinding. In this report, time-lapse video microscopy was used to examine RGC growth cones as they interacted with a sharp border between two substrates normally encountered in vivo. Growth cones displayed active responses upon contact with a new substrate: crossing, turning to remain on the first substrate, collapse, and retraction were responses that occurred with frequencies dependent upon the order of substrate contact. Extensive changes in growth cone morphology were also observed during interaction with a new substrate. The va- riety of behaviors exhibited at borders suggests that the growth cones were actively influenced by contact with a new substrate.

Growth cones of different neuronal origin have been shown to exhibit a number of behaviors in response to contact with other cells or molecules in vitro (Kapfhammer et al., 1986; Kapfhammer and Raper, 1987b; Honig and Burden, 1993; Oakley and Tosney, 1993; Gomez and Letourneau, 1994) as well as in vivo (O'Connor et al., 1990; Kaethner and Stuermer, 1992; O'Connor and Bentley, 1993; Godement et al., 1994; Halloran and Kalil, 1994). Some of these responses could be considered a response to an attractive cue, for example, crossing behavior. In all substrate combinations examined, growth cones were observed to cross onto the new substrate with fairly high frequency. This response was not surprising since RGC axons grow readily on these substrates when presented individually. An important finding was that growth cones illustrated a weak preference for $\mathrm{N}$-cadherin or $\mathrm{L} 1 / 8 \mathrm{D} 9$ over laminin. This slight preference was exhibited in two ways. First, more than one-third of the growth cones initiating on L1/8D9 or N-cadherin turned after contact with the laminin border to remain on the first substrate. Second, a significant delay in forward growth was illustrated by more than one-third of the growth cones after contact with the laminin border, regardless of whether the growth cones crossed or turned. Together, these results suggest that laminin was not inhibitory to the growth cones, but rather was the less preferable substrate of the two available. This result was not detected in previous studies of cultures at fixed time points, in which a 

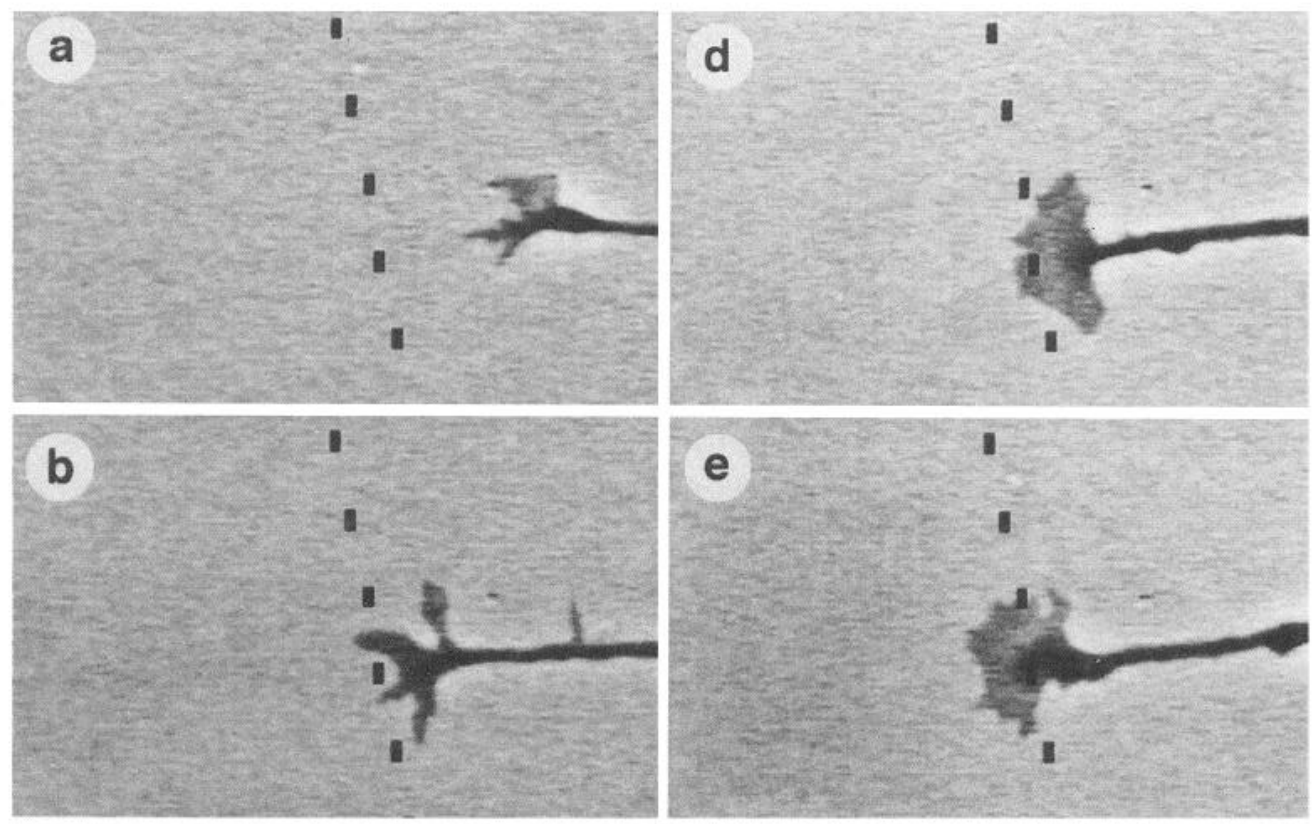

Figure 4. Time-lapse series of a growth cone initiating growth on laminin and contacting L1/8D9 at a border region. Images of the growth cone are shown at 0:00 (a), 7:30 (b), 9:30 (c), 16:30 $(d), 21: 30(e)$, and $37: 30(f) \mathrm{min}$ progressed time from first frame $(a)$ (time denoted as min:sec). The border is indicated by the dashed line. The growth cone collapses $(c)$ within minutes of initial contact with the L1/8D9 (b). Upon recovery and second contact with the L1/8D9 $(d)$, the growth cone is observed to rapidly change to the large, fan-shaped morphology normally observed on L1/8D9 even though a large portion of the growth cone remains on laminin. The growth cone crosses rapidly onto the L1/8D9 after second contact with the border $(d-f)$. Scale bar, $10 \mu \mathrm{m}$.
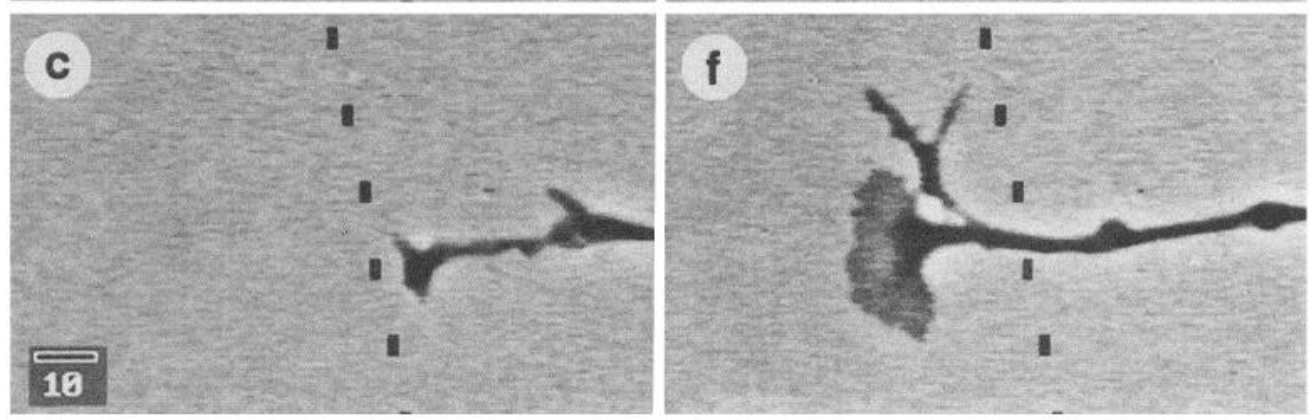

population of neurites was examined after interaction with several consecutive borders between substrates (Lemmon et al., 1992). In those studies, the response of the overall neurite population was examined instead of individual growth cones; therefore, the indicators of weak preference discussed above were not apparent. In the present study, all growth cones initiating on laminin crossed onto either L1/8D9 or N-cadherin with only a short delay after contact. These results further support the idea that although each of the substrates tested was permissive for growth, they elicited different responses from the growth cones.

Growth cones growing from L1/8D9 or N-cadherin to the laminin border often extended several filopodial processes transiently onto the laminin, as if sampling the new substrate. This behavior was observed regardless of whether the growth cone eventually crossed onto the laminin or turned at the border. A similar sampling response has been shown to precede crossing or turning behavior by mouse RGC neurons interacting with the chiasm region in vivo (Godement et al., 1994), as well as for chick dorsal root ganglion neurons interacting with a border of laminin and fibronectin in vitro (Gomez and Letourneau, 1994), and chick RGC neurons interacting with a border of laminin and chondroitin sulfate proteoglycan (CS-PG), an inhibitory molecule for neurite outgrowth (Snow et al., 1991). It is interesting that RGC growth cones turn to avoid a sharp border of CS-PG, but are capable of growing up a CS-PG gradient (Snow and Letourneau, 1992), suggesting that growth cones are able to adjust to gradual changes in environmental conditions. Filopodia have been shown to act as individual sensory units (Davenport et al., 1993) and are required for appropriate pathfinding (Bentley and Toroian-Raymond, 1986; Chien et al., 1993), and a stabilized filopodial contact is capable of changing growth cone directionality in vivo (O'Connor and Bentley, 1993). Thus, in the present study, the filopodia may have been acting as sensors to integrate the substrate cues available prior to execution of the final observed behavior.

Growth cones underwent dramatic changes in morphology upon contact with the border region and during growth on the new substrate. Growth cones initiating on L1/8D 9 or N-cadherin underwent a $40 \%$ decrease in area within the first minute of lead edge contact with laminin. This rapid decrease in size occurred prior to contact by the entire growth cone with the laminin, and may be the result of an intracellular signal (Hynes, 1992) that spread throughout the growth cone from the site of laminin contact. A laminin-induced change in growth cone morphology has also been observed by Rivas and colleagues using soluble laminin puffed onto sympathetic neurons (Rivas et al., 1992). After growth cones completed crossing onto the laminin, the growth cone area was observed to decrease a total of approximately $60 \%$, a value that corresponds well with previous measurements (Payne et al., 1992). In the converse situation, growth cones initiating on laminin underwent a $20 \%$ increase in area within the first minute of $\mathrm{N}$-cadherin contact, and an additional $70 \%$ increase during the following $4 \mathrm{~min}$. A completed crossing onto $\mathrm{N}$-cadherin resulted in a $188 \%$ total increase in growth cone area. Growth cones contacting L1/8D9 from laminin underwent an approximately $50 \%$ increase in size within the first minute 

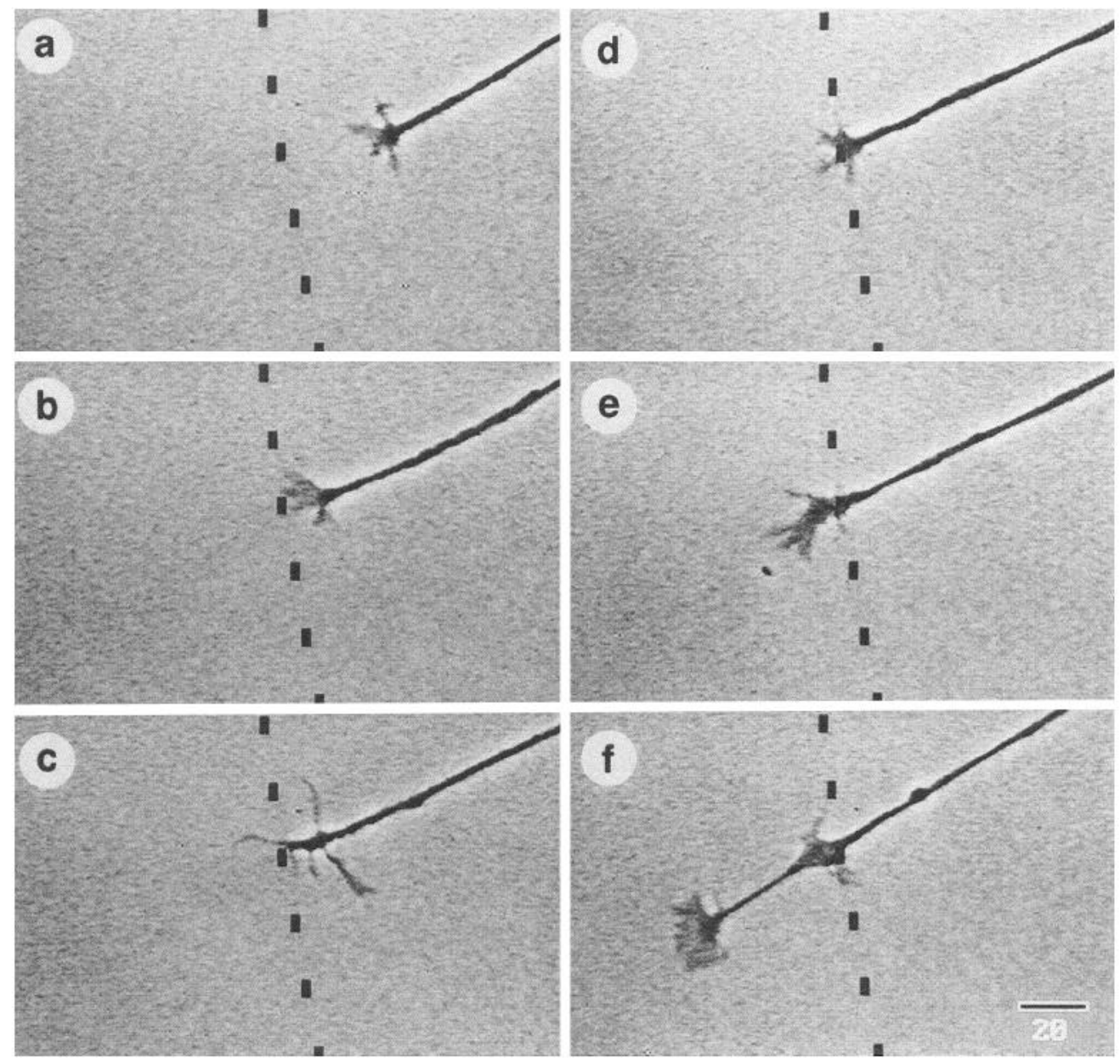

Figure 5. Time-lapse series of a growth cone initiating growth on laminin and contacting L1/8D9 at a border region. Images of the growth cone are shown at 0:00 (a), 8:30 (b), 11:00 (c), 13:30 $(d), 17: 00(e)$, and 28:00 $(f) \mathrm{min}$ progressed time from first frame $(a)$ (time denoted as min:sec). The growth cone on laminin possesses a bulbous central region with several slender processes $(a)$. In contrast, on L1/8D 9 the growth cone is much larger with a fanshaped lamellipodium $(f)$. The border is indicated by the dashed line. Note that within minutes of initial contact with $\mathrm{L} 1 / 8 \mathrm{D} 9$, the growth cone transiently collapses $(c)$, indicated by the loss of lamellipodial veils and the phase-bright appearance of the growth cone body. The growth cone recovers rapidly for continued forward progress (d). Minimal delay is observed between initial contact and resultant cross onto the L1/8D9 $(b-e)$. Scale bar, 20 $\mu \mathrm{m}$. that changed little during the following $4 \mathrm{~min}$. Once the growth cones had completed crossing onto L1/8D9, the growth cone area was observed to increase to a total of $169 \%$. These results demonstrate an enlargement of growth cone area induced by CAM contact when growth cones initiate on laminin. Again, since the growth cones changed size quickly and were not in full contact with the CAM when the change occurred, this change is probably elicited via activation of an intracellular signal. Several investigators have suggested that neurite growth stimulated by $\mathrm{N}$-cadherin or L1/8D 9 is dependent upon the activation of second messenger pathways (Doherty and Walsh, 1992, 1994; Halbach et al., 1992; Ignelzi et al., 1994). It is possible that specific changes in growth cone morphology and motility in response to contact with CAMs may also be a result of activation of second messenger pathways, but this has not yet been shown. The change in growth cone area is not primarily due to adhesive properties of the new substrate, since RGC growth cones adhere equally to laminin and N-cadherin (Lemmon et al., 1992), but are significantly larger on N-cadherin than on laminin (Payne et al., 1992).

A collapse response has often been attributed to an inhibitory interaction, especially when associated with retraction of the growth cone (Kapfhammer and Raper, 1987a; Ivins and Pittman, 1989; Davies et al., 1990; Davies and Cook, 1991; Bastmeyer and Stuermer, 1992). Retraction often occurs in conjunction with a significant delay; for example, Kapfhammer and Raper described delays of greater than 15-30 min after the retraction of a retinal growth cone from a sympathetic neurite, and vice versa
(Kapfhammer and Raper, 1987a). During the course of the retraction that they observed, the growth cone maintained residual filopodial contacts with the neurite, and reapproached the same neurite after the delay. These results are somewhat different than those described here. First, only one-third of the collapse responses observed were associated with a retraction, and in all cases the growth cones recovered to their initial size and resumed forward movement within $5 \mathrm{~min}$ of retraction. None of the growth cones maintained filopodial contact with the border region during retraction. Of the growth cones initiating on $\mathrm{N}$-cadherin that retracted at the laminin border, two turned at the border and one crossed onto laminin. All of the growth cones initiating on laminin crossed onto L1/8D9 after recovery from retraction. Due to the transient nature of the retraction, it seems that this response was not indicative of an inhibitory interaction. Rather, the initial collapse and retraction may signify a large, transient change in a second messenger, and subsequently the underlying cytoskeleton, that is produced as a result of contact with the new substrate. If adaptation to the second messenger occurs within the growth cone, then a second contact with the new substrate might not be expected to elicit a retraction, as was observed here.

Two-thirds of the growth cones that collapsed did so without an accompanying retraction. Collapse always coincided with contact with the border, or within a few minutes, suggesting that interaction with the new substrate evoked this response. Of growth cones initiating on L1 or $\mathrm{N}$-cadherin, more than half were observed to turn at the border following collapse. Collapse 
Figure 6. Time-lapse series of a growth cone initiating growth on L1/ 8D9 and contacting laminin at a border region. Images of the growth cone are shown at 0:00 (a), 6:00 (b), 8:30 (c), 10:30 $(d), 13: 30(e)$, and 26:30 $(f) \mathrm{min}$ progressed time from first frame $(a)$ (time denoted as min:sec). The border is indicated by the dashed line. Compare the large, fan-shaped morphology of the growth cone on $\operatorname{L1} / 8 \mathrm{D} 9(a, b)$ with the more consolidated, branched growth cone on laminin $(f)$. The growth cone decreases size rapidly within minutes of initial contact with laminin $(b-d)$, and in this case does not delay long before crossing onto the laminin. Scale bar, $20 \mu \mathrm{m}$.
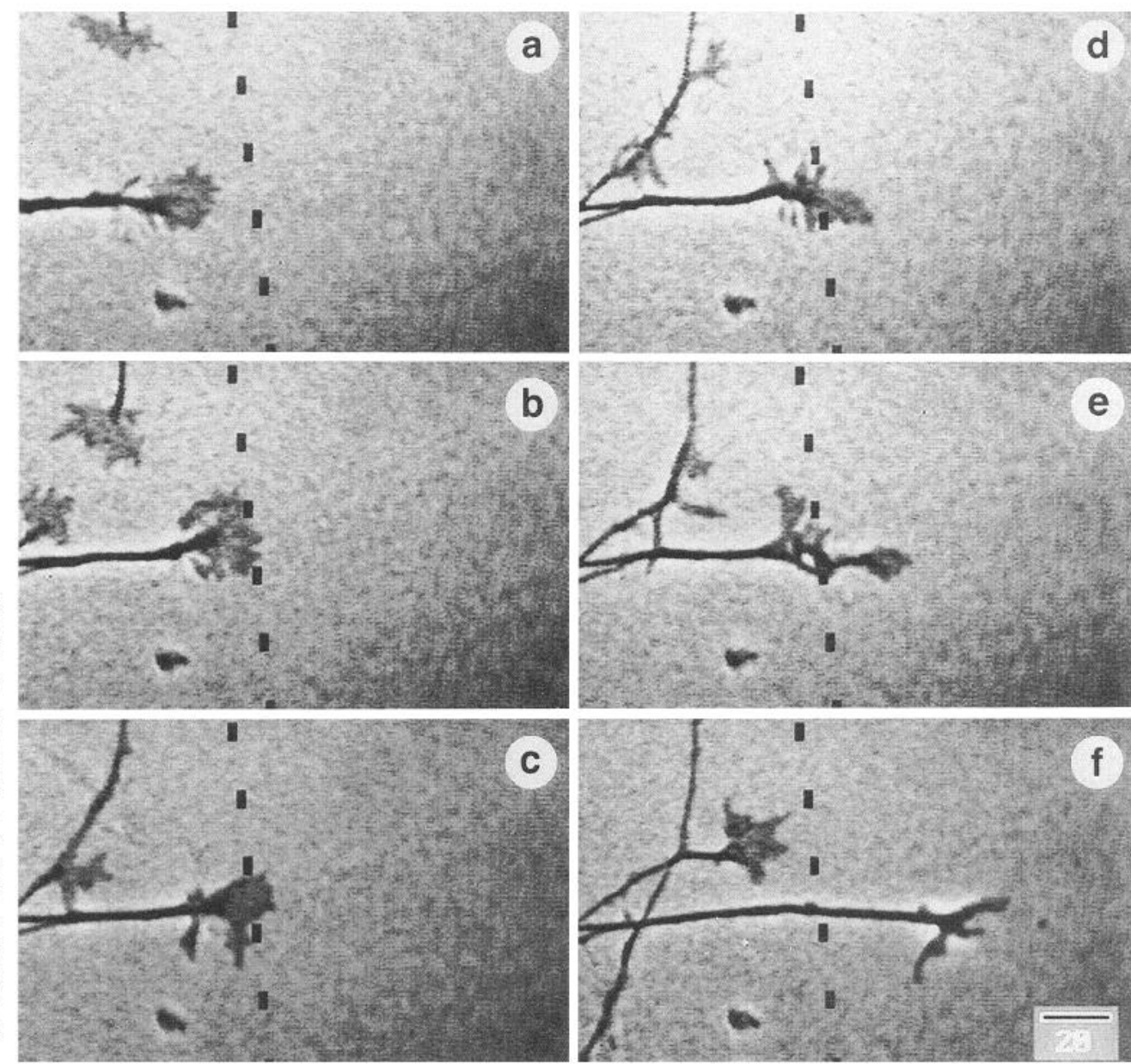

was most common in growth cones initiating on laminin, and in this case was always followed by crossing onto the adjacent CAM. These results suggest that collapse may be a general behavior that occurs in response to abrupt changes in the growth environment, and may not be indicative of inhibitory influences in all cases. This idea is supported by other time-lapse studies of growth cones in vivo in which transient collapse has been observed to occur in regions where axons normally extend (Godement et al., 1994; Halloran and Kalil, 1994).

$\mathrm{N}$-cadherin, $\mathrm{L} 1$, and laminin have been suggested to interact with the cytoskeleton as a result of ligand-receptor binding (Hirano et al., 1987; Hynes and Lander, 1992; Davis et al., 1993; Gumbiner, 1993; Davis and Bennett, 1994). In addition, the distribution of RGC growth cone cytoskeletal elements differs depending upon the growth substrate (Burden-Gulley and Lemmon, unpublished observations). Therefore, the collapse observed here may be due to specific rearrangements of cytoskeletal elements triggered by contact with a new growth-promoting molecule. Rearrangements in growth cone cytoskeletal elements, specifically filamentous actin and microtubules, in response to collapse have been demonstrated by other investigators (Lankford and Letourneau, 1989; Fan et al., 1993).

The results described above suggest that a second messenger pathway is altered when growth cones detect a sharp border between two growth-promoting molecules. One of the more likely candidates involved in this response is intracellular calcium $\left(\left[\mathrm{Ca}^{2+}\right]_{i}\right)$. In some (Cohan et al., 1987; Bandtlow et al., 1993), but not all (Ivins et al., 1991), cases of growth cone collapse, changes of $\left[\mathrm{Ca}^{2+}\right]_{i}$ within the growth cone have been observed. It is interesting that the triggering of L1 or NCAM on the surface of PC12 cells, cerebellar neurons, or dorsal root ganglion neurons by purified CAMs or CAM-directed antibodies has been reported to alter $\left[\mathrm{Ca}^{2+}\right]_{i}$ (Schuch et al., 1989; Halbach et al., 1992). In addition, neurite outgrowth stimulated by L1, N-cadherin, or NCAM appears to require calcium influx through Nand L-type calcium channels (reviewed in (Doherty and Walsh, 1994). Local increases in $\left[\mathrm{Ca}^{2+}\right]_{i}$, up to a threshold level, appear to be necessary for new veil formation and growth (Cohan et al., 1987; Goldberg, 1988). Above this threshold level, increased $\left[\mathrm{Ca}^{2+}\right]_{i}$ results in collapse of growth cones (Cohan et al., 1987) and inhibits neurite elongation (Silver et al., 1989). It is possible that several signaling pathways may lead to the same behavioral change in the growth cone, namely, collapse. This idea is supported by results of Igarashi and colleagues, in which growth cone collapse induced by several different stimuli was shown to be mediated by $\mathrm{G}$ protein-coupled receptors (Igarashi et al., 1993).

Due to the many instances of growth cone collapse observed in the present study when growth cones encountered growthpromoting rather than growth-inhibiting substrates, one must reassess the function of the collapse response. Does collapse with its associated disassembly of the existing cytoskeleton promote efficient reorganization of the cytoskeleton into a new configuration more suitable for a novel environment? For example, would collapse speed the transition from an integrin-based mode of translocation to a CAM-mediated one? The different time 

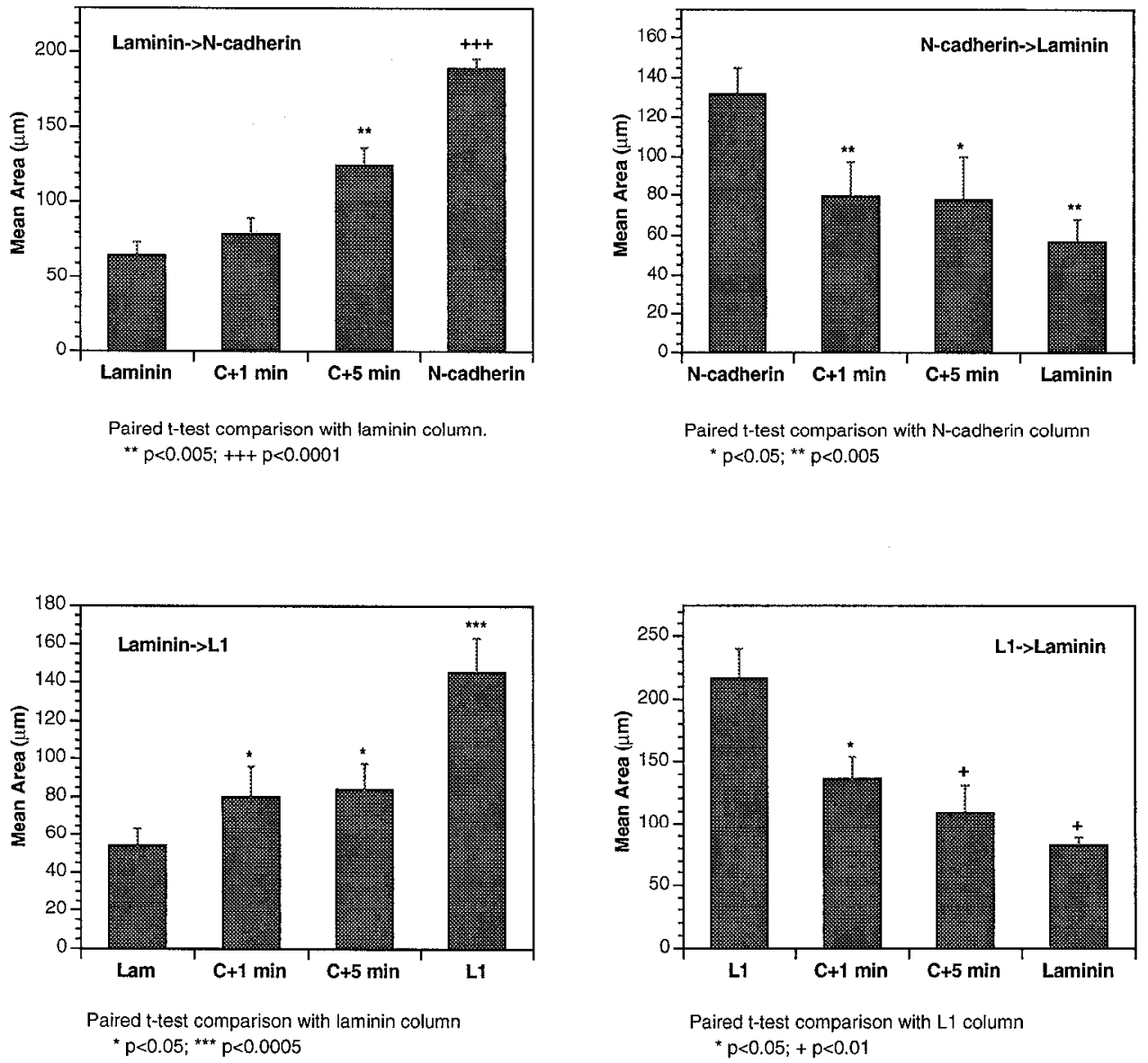

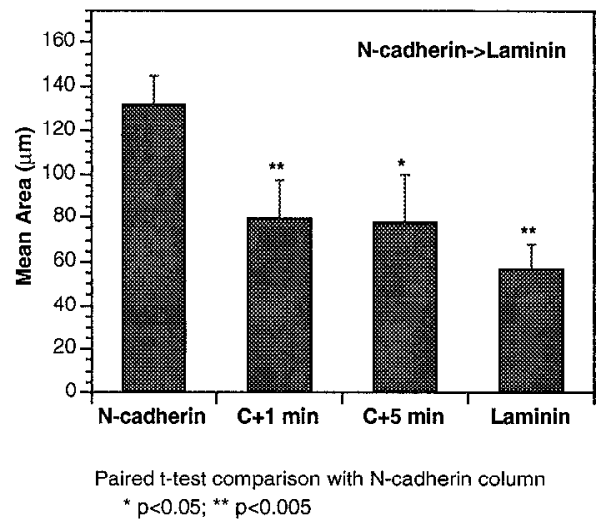

Figure 7. Comparison of mean growth cone area. The growth cone area was measured during growth on the first substrate prior to border contact, 1 min after contact $(C+1 \mathrm{~min}), 5$ min after contact $(C+5$ min $)$, and after completed cross onto the second substrate. Top left, Growth cones initiating on laminin and crossing onto $\mathrm{N}$-cadherin $(n=11)$. Top right, Growth cones initiating on $\mathrm{N}$-cadherin and crossing onto laminin $(n=5)$. Bottom left, Growth cones initiating on laminin and crossing onto L1/8D9 $(n=11)$. Bottom right, Growth cones initiating on L1/8D9 and crossing onto laminin $(n=5)$. Mean results from each category were compared using the paired Student's $t$ test: *, $p<0.05 ;+, p<$ $0.01 ; * *, p<0.005 ; * * *, p<0.0005$; ,$+++ p<0.0001$. course observed in the present study for collapse and delay induced by growth-promoting substrates compared with inhibitory molecules (Kapfhammer and Raper, 1987a,b; Cox et al., 1990; Davies et al., 1990; Luo et al., 1993) raises the possibility that these different forms of collapse are produced by not just quantitative differences in intracellular signals such as calcium levels,

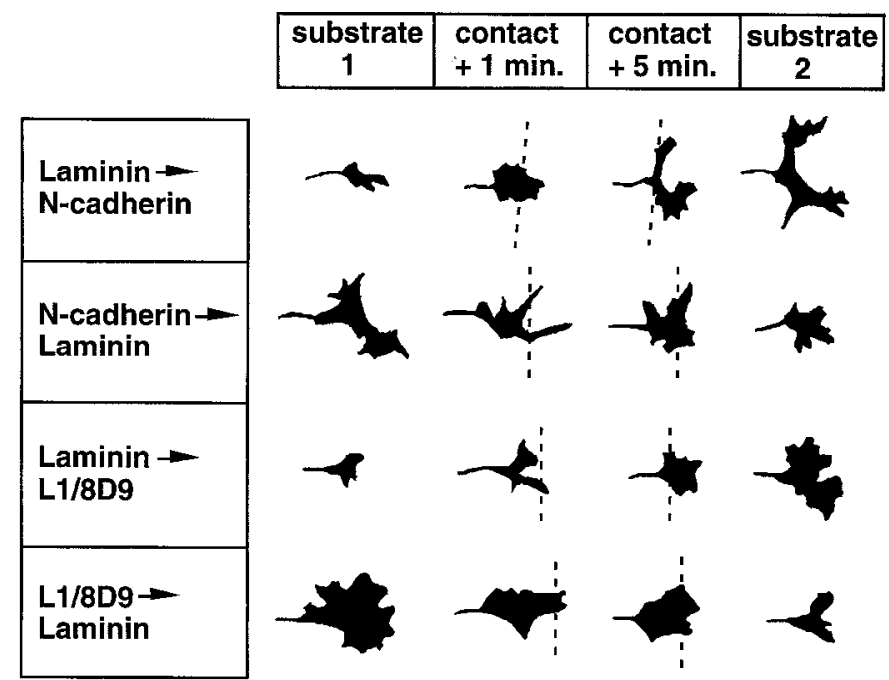

Figure 8. Summary of morphologic changes during border interaction. Representative traces of growth cones prior to border contact, 1 min after border contact, 5 min after border contact, and after completed cross onto the second substrate are shown. The dashed line represents the border between substrates. but may imply that there are qualitative differences such as the involvement of different second messenger systems. In support of this idea, Finnegan and colleagues determined that collapse and retraction of goldfish retinal ganglion cell axons in response to monoclonal antibody $8 \mathrm{~A} 2$ were not due to alteration of intracellular calcium concentration, but rather to elevated phosphorylation levels mediated by protein kinase $\mathrm{C}$ and a tyrosine kinase (Finnegan et al., 1993). Further studies on the proximal events in CAM- and integrin-mediated signals in growth cones are clearly required in order to understand the function of these molecules in axonal pathfinding.

\section{References}

Bandtlow CE, Schmidt MF, Hassinger TD, Schwab ME, Kater SB (1993) Role of intracellular calcium in NI-35-evoked collapse of neuronal growth cones. Science 259:80-83.

Rastmeyer M, Stuermer CAO (1992) Behavior of fish retinal growth cones encountering chick caudal tectal membranes: a time-lapse study on growth cone collapse. J Neurobiol 24:37-50.

Bentley D, Toroian-Raymond $\Lambda$ (1986) Disoriented pathfinding by pioneer neurone growth cones deprived of filopodia by cytochalasin treatment. Nature 323:712-715.

Bixby JL, Jhabvala P (1990) Extracellular matrix molecules and cell adhesion molecules induce neurites through different mechanisms. J Cell Biol 111:2725-2732.

Bixby JL, Zhang $\mathrm{K}$ (1990) Purified $\mathrm{N}$-cadherin is a potent substrate for the rapid induction of neurite outgrowth. J Cell Biol 110:12531260.

Bovolenta P, Mason C (1987) Growth cone morphology varies with position in the developing mouse visual pathway from retina to first targets. J Neurosci 7:1447-1460.

Brittis PA, Canning DR, Silver J (1992) Chondroitin sulfate as a regulator of neuronal patterning in the retina. Science $255: 733-736$. 
Chien C, Rosenthal DE, Harris WA, Holt CE (1993) Navigational errors made by growth cones without filopodia in the embryonic Xenopus brain. Neuron 11:237-251.

Cohan CS, Connor IA, Kater SB (1987) Flectrically and chemically mediated increases in intracellular calcium in neuronal growth cones. J Neurosci 7:3588-3599.

Cohen J, Burne JF, McKinlay C, Winter J (1987) The role of laminin and the laminin/fibronectin receptor complex in the outgrowth of retinal ganglion cell axons. Dev Biol 122:407-418.

Cox EC, Muller B, Bonhoeffer F (1990) Axonal guidance in the chick visual system: posterior tectal membranes induce collapse of growth cones from the temporal retina. Neuron 4:31-37.

Davenport RW, Dou P, Rehder V, Kater SB (1993) A sensory role for neuronal growth cone filopodia. Nature 361:721-724.

Davies JA, Cook GMW (1991) Growth cone inhibition-an important mechanism in neural development? Bioessays 13:11-15.

Davies JA, Cook GMW, Stern CD, Keynes RJ (1990) Isolation from chick somites of a glycoprotein fraction that causes collapse of dorsal root ganglion growth cones. Neuron 2:11-20.

Davis JQ, Bennett V (1994) Ankyrin binding activity shared by the Neurofascin/L1/NrCAM family of nervous system cell adhesion molecules. J Biol Chem 269:27163-27166.

Davis JQ, McLaughlin T, Bennett V (1993) Ankyrin-binding proteins related to nervous system cell adhesion molecules: candidates to provide transmembrane and intercellular connections in adult brain. $\mathrm{J}$ Cell Biol 121:121-133.

Dodd J, Jessell TM (1988) Axon guidance and the patterning of neuronal projections in vertebrates. Science 242:692-699.

Doherty P, Walsh FS (1992) Cell adhesion molecules, second messengers and axonal growth. Curr Opin Neurobiol 2:595-601.

Doherty P, Walsh FS (1994) Signal transduction events underlying neurite outgrowth stimulated by eell adhesion molecules. Curr Opin Neurobiol 4:49-55.

Doherty P, Ashton SV, Moore SE, Walsh FS (1991) Morphoregulatory activities of NCAM and N-cadherin can be accounted for by $\mathrm{G}$ protein-dependent activation of $\mathrm{L}$ - and $\mathrm{N}$-type calcium channels. Cell 67:21-33.

Drazba J, Lemmon V (1990) The role of cell adhesion molecules in neurite outgrowth on Mueller cells. Dev Biol 138:82-93.

Fan J, Mansfield SG, Redmond T, Gordon-Weeks PR, Raper JA (1993) The organization of $\mathrm{f}$-actin and microtubules in growth cones exposed to a brain-derived collapsing factor. J Cell Biol 121:867-878.

Finnegan SG, Lemmon VP, Koenig E (1993) Monoclonal antibody 8A2-induced retraction appears to be mediated by protein phosphorylation in goldfish retinal ganglion cell axons. Dev Biol 156:230242.

Godement P, Salaun J, Mason CA (1990) Retinal axon pathfinding in the optic chiasm: divergence of crossed and uncrossed fibers. Neuron 5:173-186.

Godement P, Wang LC, Mason CA (1994) Retinal axon divergence in the optic chiasm: dynamics of growth cone behavior at the midline. J Neurosci 14:7024-7039.

Goldberg DJ (1988) Local role of calcium in formation of veils in growth cones. J Neurosci 8:2596-2605.

Gomez TM, Letourneau PC (1994) Filopodia initiate choices made by sensory neuron growth cones at laminin/fibronectin borders in vitro. J Neurosci 14:5959-5972.

Grenningloh G, Rehm EJ, Goodman CS (1991) Genetic analysis of growth cone guidance in Drosophila: fasciclin II functions as a neuronal recognition molecule. Cell 67:45-57.

Gumbiner BM (1993) Proteins associated with the cytoplasmic surface of adhesion molecules. Neuron 11:551-564.

Halbach FB, Taylor J, Schachner M (1992) Cell type-specific effects of the neural adhesion molecules L1 and N-CAM on diverse second messenger systems. Eur J Neurosci 4:896-909.

Halfter W, Newgreen DF, Sauter J, Schwarz U (1983) Oriented axon outgrowth from avian embryonic retinae in culture. Dev Biol 95:5664

Halloran MC, Kalil K (1994) Dynamic behaviors of growth cones extending in the corpus callosum of living cortical brain slices observed with video microscopy. J Neurosci 14:2161-2177.

Hammarback JA, McCarthy JB, Palm SL, Furcht LT, Letourneau PC (1988) Growth cone guidance by substrate-bound laminin pathways is correlated with neuron-to-pathway adhesivity. Dev Biol 126.

Hatta K, Takeichi M (1986) Expression of N-cadherin adhesion mol- ecules associated with early morphogenetic events in chick development. Nature 320:447-449.

Heffner CD, Lumsden AGS, O'Leary DDM (1990) Target control of collateral extension and directional axon growth in the mammalian brain. Science 247:217-220.

Hirano S, Nose A, Hatta K, Kawakami A, Takeichi M (1987) Calciumdependent cell-cell adhesion molecules (cadherins): subclass specificities and possible involvement of actin bundles. J Cell Biol 105 $2501-2510$

Holt CE, Harris WA (1993) Position, guidance, and mapping in the developing visual system. J Neurobiol 24:1400-1422.

Honig MG, Burden SM (1993) Growth cones respond in diverse ways upon encountering neurites in cultures of chick dorsal root ganglia. Dev Biol 156:454-472.

Hynes RO (1992) Integrins: versatility, modulation, and signaling in cell adhesion. Cell 69:11-25.

Hynes RO, Lander AD (1992) Contact and adhesive specificities in the associations, migrations, and targeting of cells and axons. Cell 68: $303-322$.

Igarashi M, Strittmatter SM, Vartanian T, Fishman MC (1993) Mediation by $\mathrm{G}$ proteins of signals that cause collapse of growth cones. Science 259:77-79.

Ignelzi MA, Miller DA, Soriano P, Maness PF (1994) Impaired neurite outgrowth of src-minus cerebellar neurons on the cell adhesion molecule L1. Neuron 12:873-884.

Inuzuka H, Miyatani S, Takeichi M (1991) R-cadherin: a novel calcium dependent cell-cell adhesion molecule expressed in the retina. Neuron 7:69-79.

Ivins JK, Pittman RN (1989) Growth cone-growth cone interactions in cultures of rat sympathetic neurons. Dev Biol 135:147-157.

Ivins JK, Raper JA, Pittman RN (1991) Intracellular calcium levels do not change during contact-mediated collapse of chick DRG growth cone structure. J Neurosci 11:1597-1608.

Kaethner RJ, Stuermer CAO (1992) Dynamics of terminal arbor formation and target approach of retinotectal axons in living zebrafish embryos: a time-lapse study of single axons. J Neurosci 12:32573271 .

Kapfhammer JP, Raper JA (1987a) Collapse of growth cone structure on contact with specific neurites in culture. J Neurosci 7:201-212.

Kapfhammer JP, Raper JA (1987b) Interactions between growth cones and neurites growing from different neural tissues in culture. J Neurosci 7:1595-1600.

Kapfhammer JP, Grunewald BE, Raper JA (1986) The selective inhibition of growth cone extension by specific neurites in culture. Neurosci 6:2527-2534

Krayanek S, Goldbery S (1981) Oriented extracellular channels and axonal guidance in the embryonic chick retina. Dev Biol 84:41-50.

Lagenaur C, Lemmon V (1987) An L1-like molecule, the 8D9 antigen, is a potent substrate for neurite extension. Proc Natl Acad Sci USA 84:7753-7757.

Landmesser L (1984) The development of specific motor pathways in the chick embryo. Trends Neurosci 7:336-339.

Lankford KL, Letourneau PC (1989) Evidence that calcium may control neurite outgrowth by regulating the stability of actin filaments. $J$ Cell Biol 109:1229-1243.

Lemmon V, McLoon S (1986) The appearance of an L1-like molecule in the chick primary visual pathway. J Neurosci 6:2987-2994.

Lemmon V, Farr K, Lagenaur C (1989) Ll mediated axon outgrowth occurs via a homophilic binding mechanism. Neuron 2:1597-1603.

Lemmon V, Burden SM, Payne HR, Elmslie GJ, Hlavin ML (1992) Neurite growth on different substrates: permissive versus instructive influences and the role of adhesive strength. J Neurosci 12:818-826.

Letourneau PC (1975a) Possible roles for cell-to-substratum adhesion in neuronal morphogenesis. Dev Biol 44:77-91.

I etourneau PC. (1975b) Cell-to-substratum adhesion and guidance of axonal elongation. Dev Biol 44:92-101.

Lumsden AGS, Davies AM (1986) Chemotropic effect of specific target epithelium in the developing mammalian nervous system. Nature 323:538-539.

Luo Y, Raible D, Raper JA (1993) Collapsin: a protein in brain that induces the collapse and paralysis of neuronal growth cones. Cell 75 217-227

Matsunaga M, Hatta K, Takeichi M (1988) Role of N-cadherin cell adhesion molecules in the histogenesis of neural retina. Neuron $1: 289-295$ 
Oakley RA, Tosney KW (1993) Contact-mediated mechanisms of motor axon segmentation. J Neurosci 13:3773-3792.

O'Connor TP, Bentley D (1993) Accumulation of actin in subsets of pioneer growth cone filopodia in response to ncural and cpithelial guidance cues in situ. J Cell Biol 123:935-948.

O'Connor TP, Duerr JS, Bentley D (1990) Pioneer growth cone steering decisions mediated by single filopodial contacts in situ. J Neurosci 10:3935-3946.

Payne HR, Burden SM, Lemmon V (1992) Modulation of growth cone morphology by substrate-bound adhesion molecules. Cell Motil Cytoskel 21:65-73.

Reichardt LF, Tomaselli KJ (1991) Extracellular matrix molecules and their receptors: functions in neural development. Annu Rev Neurosci 14:531-570.

Rivas RJ, Burmeister DW, Goldberg DJ (1992) Rapid effects of laminin on the growth cone. Neuron 8:107-115.

Safell JL, Walsh FS, Doherty P (1992) Direct activation of second messenger pathways mimics cell adhesion molecule-dependent neurite outgrowth. J Cell Biol 118:663-670.

Schlosshauer B, Schwarz U, Rutishauser U (1984) Topological distribution of different forms of neural cell adhesion molecule in the developing chick visual system. Nature 310:141-143.

Schuch U, Lohse MJ, Schachner M (1989) Neural cell adhesion molecules influence second messenger systems. Neuron 3:13-20.

Seeger M, Tear G, Ferres-Marco D, Goodman CS (1993) Mutations affecting growth cone guidance in Drosophila: genes necessary for guidance toward or away from the midline. Neuron 10:409-426.

Silver J, Rutishauser U (1984) Guidance of optic axons in vivo by a preformed adhesive pathway on neuroepithelial endfeet. Dev Biol $106: 485-499$.

Silver RA, Lamb AG, Bolsover SR (1989) Elevated cytosolic calcium in the growth cone inhibits neurite elongation in neuroblastoma cells: correlation of behavioral states with cytosolic calcium concentration. J Neurosci 9:4007-4020.

Snow DM, Lctourneau PC (1992) Ncurite outgrowth on a stcp gradient of chondroitin sulfate proteoglycan (CS-PG). J Neurobiol 23:322336.

Snow DM, Watanabe M, Letourneau PC, Silver J (1991) A chondroitin sulfate proteoglycan may influence the direction of retinal ganglion cell outgrowth. Development 113:1473-1485.

Stretavan DW, Feng L, Pure E, Reichardt LF (1994) Embryonic neurons of the developing optic chiasm express L1 and CD44, cell surface molecules with opposing effects on retinal axon growth. Neuron 12:957-975.

Tang J, Landmesser L, Rutishauser U (1992) Polysialic acid influences specific pathfinding by avian motoneurons. Neuron 8:1031-1044.

Thiery JP, Duband JL, Rutishauser U, Edelman GM (1982) Cell adhesion molecules in early chick embryogenesis. Proc Natl Acad Sci USA 79:6737.

Tosney KW (1991) Cells and cell-interactions that guide motor axons in the developing chick embryo. Bioessays 13:17-23.

Williams E, Doherty P, Turner G, Reid RA, Hemperly JJ, Walsh FS (1992) Calcium influx into neurons can solely account for cell-contact dependent neurite outgrowth stimulated by transfected L1. J Cell Biol 119:883-892.

Williams EJ, Walsh FS, Doherty P (1994a) The production of arachidonic acid can account for calcium channel activation in the second messenger pathway underlying neurite outgrowth stimulated by NCAM, N-cadherin and L1. J Neurochemistry 62:1231-1234.

Williams EJ, Walsh FS, Doherty P (1994b) Tyrosine kinase inhibitors can differentially inhibit integrin-dependent and CAM-stimulated neurite outgrowth. J Cell Biol 124:1029-1037. 